\title{
On Tenor and Its Prosodic Markers in Rhetorical Discourse
}

\author{
Elena Freydina \\ Moscow State Pedagogical University \\ Correspondence concerning this article should be addressed to Elena Freydina, Moscow Pedagogical \\ State University, Prospekt Vernadskogo, bld. 88, Moscow, Russian Federation, 119571. \\ E-mail: freydina55@mail.ru
}

\begin{abstract}
In rhetorical discourse, tenors can be formed intentionally and used as rhetorical strategies to implement the speaker's goals. The article reports on a study of the contextual category 'tenor' and its prosodic realisation in rhetorical discourse. The paper examines rhetorical, auditory and acoustic features in the samples of English academic presentations (lectures). The author argues that tenors can reflect both the relationships of the participants of a particular speech event and the relationships associated with a broader sociocultural context. Analysing tenor as a sociocultural phenomenon the author demonstrates its correlations with some specific features of British speech culture. Special attetnion is given to the role of prosody in conveying and identifying tenors. The article contains an overview of the prosodic markers of tenor: tone of voice, pitch parameters, temporal characteristics. The study of tenor and its prosodic markers contributes to a fuller understanding of the influence of contextual factors on the prosodic realisation of discourse. The observations made in the paper may be useful to develop crosscultural communication competence and rhetorical competence of EFL students.
\end{abstract}

Keywords: tenor of discourse, rhetorical strategy, prosodic markers, tone of voice, irony, cross-cultural communication

The shift to a discourse perspective in the research of prosody, on the one hand, and the incorporation of prosody into discourse analysis, on the other hand, have provided a deeper insight into the social and interactional meaning of speech communication. Prosodic means are studied with regard to their functions in speech communication as well as situational and contextual factors. This complex interaction of prosody and context is reflected in tenor, a communication phenomenon linking spoken discourse and extralinguistic context.

The significance of tenor as a contextual category is generally acknowledged. Some attention is given to tenor in the studies of language variation and style (Copland, 2007), discourse theory (Karasik, 2009), sociolinguistics (Downes, 1998; Schevchenko, 2015). Interestingly, all the researchers interested in tenor tend to comment on the importance of the vocal component. However, the prosodic markers of tenor are seldom included in the analysis.

The goal of this research is to describe tenor as a contextual category in rhetorical discourse with regard to its prosodic realisation. It should also be noted that the research was aimed at establishing tenor variations and tenor shifts within a particular genre of discourse. Academic public speeches (lectures) were selected as the material for the analysis, because this genre of rhetorical discourse is generally associated with a certain tenor. The observations presented here are meant to demonstrate that the tenor in academic presentations is neither fixed nor homogeneous.

\section{Material and Methods}

The material for the analysis was the corpus of 20 lectures (Moscow Pedagogical State University (MPGU) Corpus of Spoken English, 2015) delivered by British lecturers (12 men and 8 women) and recorded at the moment of their presentation. The lectures were video recorded (9 lectures) and audio recorded (11 lectures). The topics of the lectures were related to the spheres of education, linguistics, cross-cultural communication, foreign language teaching, social and cultural problems.

Transcripts of the lectures were made. The analysis of the prosodic features was combined with the analysis of the contextual factors and rhetorical characteristics of discourse. 
Auditory (perception) analysis consisted of recording the "auditory impression" of the speech segments and providing their auditory transcription (intonation notation). Acoustic analysis (Speech Analyzer (v. 3.0.1) provided measurements of the following prosodic parameters: pitch, duration and intensity. The interpretation of the data obtained in the course of perception and acoustic analyses made it possible to establish the main tendencies in the prosodic realisation of discourse tenor.

\section{Tenor as a Contextual Category}

Tenor is generally described as a significant contextual category. It is viewed as a reflection of discourse participants' relationships. According to Gregory and Carroll (1978, p. 9), "The relationship the user has with his audience, his addressee(s), is the situational factor that is involved in tenor of discourse. Tenors of discourse result from the mutual relations between the language used and the relationships among the participants in language events". In other words, tenor carries the information about a variety of social and sociocultural properties of discourse participants which determine the character of their interaction: their social statuses and roles, their institutional roles, social distance, which ranges from very close (intimate) to very distant (formal).

However, tenor can also be associated with the goals of communication and language variations that result from the type of speech activity, from what the speaker does with the language, whether he wants to persuade, to inform, to entertain and so on. Thus, tenor as a complex contextual factor has two aspects: personal and functional. Functional participants' relationships and functional tenor as well as interpersonal relationships are a source of significant linguistic variation. It should be noted that functional tenor is often associated with style ("conversational tenor" - "conversational style"). In the analysis of personal tenor the following parameters are relevant: formal-informal, friendly - hostile, polite - impolite, etc. Clearly, both dimensions of tenor reflect the most subtle attitudes that emerge in the process of speech interaction and contribute to creating a certain atmosphere.

It should be mentioned that tenors are formed by all the participants of discourse. Thus, in public speaking both the speaker and the audience will constitute the tenor. One of the assumptions this paper is based upon is that tenors can reflect not only the relationships of the participants of a particular speech event but also the relationships associated with a broader sociocultural context.

\section{Tenor and Prosody}

Admittedly, in oral discourse the vocal features are of primary importance in conveying tenors. As a contextualization cue, prosody provides the links between the message and the social context of interaction, participants' relationships in particular. Prosodic features can serve as signals that make it possible for the hearer to identify the tenor conveyed by the speaker.

Interestingly, the notion of tenor is similar to the notion of tone, or tone of voice, which is sometimes used to describe the emotional and attitudinal aspect of interaction: "I don't like this tone", "Why this hostile tone?", etc. In other words, it is the tone of voice that leads to inferences about the tenor of discourse.

According to Couper-Kuhlen and Selting (1996), "in spoken interaction we react to a lot more than the words our utterances are made up of: 'a tone of voice', a 'feeling' about the way our partner spoke, the 'atmosphere' of a conversation - these are often more significant cues to the real message than the words themselves" (Couper-Kuhlen, Selting, 1996, p. 1).

The atmosphere of communication as a factor that is relevant for the adequate interpretation of the message and that influences speech interaction is also referred to as 'keying'. Downes (1998) defines 'key' as "tone, manner and spirit" of the speech act (Downes, 1998, p. 303). Keying is very important for identifying (in most cases inferring) the speaker's intention, whether he is serious or ironic, friendly or hostile, etc. This component of communicative events is sometimes described as 'voicing', "which can be playful or malicious, acts of teasing or put-downs" (Coupland, 2007, p. 114).

It can be seen from this brief overview that most descriptions of the contextual category 'tenor' contain a reference to the vocal features ('tone of voice', 'voicing'), which shows the significance of phonetic means in conveying and identifying tenors of discourse.

In phonetic literature, the tone of voice, a complex vocal phenomenon, is described as a carrier of emotive indexical information. Expressing the speaker's emotional state and his attitude to the message, the addressee and the situation, it can "regulate speech interaction and is connected with the manner and style of interaction" (Kreydlin, 2000, p. 497).

Pitch parameters also contribute to tenor formation and serve as markers of tenor. Thus, Schevchenko (2015) claims that pitch characteristics in general and terminal tones in particular play an important role in creating the atmosphere of friendliness and empathy (Schevchenko, 2015, p. 205). It is true to say that performing its attitudinal function, intonation can convey a variety of attitudinal meanings related to different aspects of communication. In particular, it reflects the character of personal relationships in the dynamics of discourse. However, it should be noted that 
the process of matching a particular intonation pattern with a particular attitude is far from straightforward. According to Roach (2000),

the notion of "expressing an emotion or attitude" is itself a more complex one than is generally realised. First, an emotion may be expressed involuntarily or voluntarily; if I say something in a "happy" way, this may be because I feel happy, or because I want to convey to you the impression that I am happy. Second, an attitude that is expressed could be an attitude towards the listener (e.g. if I say something in a "friendly" way), towards what is being said (e.g. if I say something in a "sceptical" or "dubious" way) or towards some external event or situation (e.g. "regretful" or “disapproving”). (Roach, 2000, p. 185)

It follows from this that the study of 'attitudinal intonation' involves the analysis of the context, in particular, 'speaker meaning' and the way it is perceived and interpreted by the hearer.

What needs to be stressed here is that when studying the role of particular intonation parameters (key, pre-nuclear patterns, nuclear tones) in conveying tenors, special attention should be given to a very detailed analysis of all the contextual factors: the goal of communication, the form and mode of discourse, the norms of speech culture, etc. This analysis will make it possible to identify the correlation between message, intonation and context and make some inference about the tenor of discourse.

\section{Results and Discussion}

\section{Prosodic Markers of Tenor in Public Speeches}

Researchers interested in social and interactional meaning, reflected in the tenor of discourse, are faced with three problems: firstly, it is not possible to ascribe a certain tenor to a particular genre of discourse, secondly, tenors can change in the process of interaction, and thirdly, tenor may be difficult to identify, especially in cross-cultural communication.

Admittedly, tenor is an indicator of how the utterance is perceived by the hearer: whether it is neutral or emotional, friendly or unfriendly, amusing or serious. The classification of communicative tenors, suggested by Karasik (2009), includes such types of tenor as informative, phatic, solemn, fascinating, aggressive, manipulative, jocular, didactic and others (Karasik, 2009, p. 306). It is obvious that some of these tenors are generally associated with a particular type of discourse: phatic tenor is typical of small talk, solemn can be expected in oratory, didactic tenor can be observed in pedagogical discourse. However, in actual speech interaction, tenors may vary within the same genre of discourse: a lecture may be characterised by a combination of informative, didactic and jocular tenors.

As regards the problem of identifying tenors in cross-cultural communication broad sociocultural context is to be considered. As it was already mentioned, the choice of tenor results from the cultural norms of speech interaction, which prescribe certain patterns of speech behaviour.

The author's primary concern is to investigate various sources of tenor in rhetorical discourse and give an overview of prosodic markers of tenor with regard to contextual factors.

One of the problems we are faced with is that in goal-oriented rhetorical discourse tenors can be "constructed". In other words, the speaker may be expected to project the sort of tenor, which will contribute to the effectiveness of his interaction with the listeners. The impression of friendly informal tenor of discourse may not necessarily result from the relationship of the speaker and the audience considered on the personal axis. The speaker may intentionally choose friendly informal tenor as an instrument of building rapport with the listeners so that to implement the goals of the speech.

The analysis of the corpus of lectures demonstrates that about $70 \%$ of lecturers choose the informal tenor, $15 \%$ combine the formal and informal interaction and only $15 \%$ of the academic public presentations are characterised by the formal tenor.

What needs to be stressed here is that the informal tenor in a public speech is not identical to the informal tenor of everyday conversation. Informal conversational interaction is characterised by minimal control of the verbal and non-verbal input of the participants: their posture may be relaxed, they may speak in low voices, use self-repair and hesitation pauses extensively. In rhetorical discourse, speakers are expected to control their volume, to vary the tempo of speech and melodic repertoire, and in general to avoid the speech behavior that might be perceived as lack of rhetorical competence.

However, the data obtained in the course of perception and acoustic analysis demonstrated marked prosodic differences, which result from the difference in tenors.

\section{Prosodic Markers of Informal Tenor}

\section{Pitch Characteristics:}

Pitch ranges vary from narrow to medium (4-18 semitones);

The most frequent terminal tones: Low Fall, Mid Fall, Mid Level Tone, Low Rise, Fall-Rise;

Pre-nuclear patterns (Heads): Low Level Head, Mid Level Head, Falling Head, Sliding Head. 


\section{Temporal Characteristics:}

Rate of speech varies from fast to medium (125-200 milliseconds), with fast rate predominating;

The duration of syntactic pauses varies from very short to medium (250-600 milliseconds); the duration of emphatic pauses varies from 250 to 800 milliseconds; hesitation pauses (both filled and unfilled) are present, their length varies from 200 to 1600 milliseconds.

These data can be compared with the set of prosodic parameters typical of the formal tenor.

\section{Prosodic Markers of Formal Tenor}

\section{Pitch characteristics:}

Pitch ranges are greatly varied (7-25 semintones), medium and broad ranges predominate;

The prevailing terminal tones: High Fall, FallRise, Rise-Fall-Rise, Low Rise in non-final intonation groups;

Pre-nuclear patterns (Heads): High Level Head, Falling Head, Sliding Head, Stepping Head.

\section{Temporal Characteristics:}

Rate of speech varies from medium to slow (185 250 milliseconds).

The duration of syntactic pauses varies from short to very long (250-1400 milliseconds); the duration of emphatic pauses varies from 200 to 1600 milliseconds; the number of hesitation pauses is insignificant.

Loudness is not included in the comparative analysis because this prosodic feature is determined mostly by such factors as the size of the audience and the speaker's individual style and is not relevant as a marker of tenor.

It is evident that tenor is reflected on the prosodic level. Another important conclusion to draw here is the complexity of tenor as a contextual category. In rhetorical discourse, personal and functional tenors are inseparably connected and contribute to the formation of a particular style of interaction.

\section{Tenor Shifts}

As it was already mentioned tenors tend to change within the same speech act. Considering that public speaking involves active interaction of the speaker and the audience and is tailored to implement specific goals, the study of tenor in this genre of discourse can provide information about tenor variations.

We shall now turn to a series of examples illustrating how tenors function in rhetorical discourse. As it was already mentioned, two types of tenor can be traced in academic public presentations: formal (informative) tenor and informal (conversational) tenor.

'So having established that the next important point is $\mid$ how much of the income that is disposed is disposed on the basic necessities of lifel| That used to be very much easier to define in the old days $\|$ But since the middle of the last century\| we have become | a consumer society|| The evidence of this $\mid$ you can see every time you walk down Guilford High Street||... It's amazing at this time of the year| when we are just running up to the big Christmas spending spree| how the most ordinary things are advertised as being absolutely essential for your daily lifell How we ever survived without them I can't think $\|$ '. (Moscow State Pedagogical University (MSPU), 2015)

This extract demonstrates the shift of tenor within one section of the lecture on social and economic problems. In the first three sentences, tenor can be described as formal, serious, informative. It is typical of academic discourse aimed at conveying information and easily identified: the use of terms, lexical density, and syntactic precision. On the phonetic level, the following parameters are relevant: distinct enunciation, particular articulatory precision; slow tempo, long syntactic pauses, broad pitch range, the use of such terminal tones as Low Fall, High Fall, Fall-Rise, the use of Stepping Head and Sliding Head. The prosodic devices used by the speaker contribute to creating the atmosphere of serious interaction in which the interpersonal aspect is effaced in favour of the main communicative goal - getting the information across to the listeners. It is very vividly expressed in the following phrase:

But $\backslash$ since the "middle of the "last \century\|

we have $\rightarrow$ become |a consumer $\backslash$ society $\mid$

Very slow tempo, increased length of the syntactic pause between the intonation groups, word-by-word accentuation, the use of the Low Fall in non-final position, the use of emphatic pause are markers of serious informative tenor.

In the last three sentences of the extract, a marked change of tenor can be observed. The speaker supports the first statements with an example, referring both to her own experience and to the experience of the listeners. The tenor in this section can be characterised as friendly, conversational and ironic. The change of tenor is expressed both on the lexical and syntactic levels: absence of terms, colloquial expressions, simple syntactic constructions. The shift of tenor is immediately identified by the change of timber. On the prosodic level, it is marked by faster tempo, medium and narrow pitch range, and greater variety of intonation patterns: use of Mid-Level Tones and Low Falls, Mid and Low Level Tones in pre-nuclear parts of the intonation groups alongside with such intonation patterns as Sliding Head+ High Fall.

In a broad sense, the change of tenor involves a change of language and certain prosodic contrasts, 
that serve both as markers of tenor shift and as a means of identifying it.

Our basic assumption is that tenor should be studied with regard to the specific features of a particular genre of discourse. The study of academic public presentations (Bloch, Freydina, 2011; Freydina, 2013) provided some data demonstrating that both the choice of tenor and tenor shifts are determined by the rhetorical factors. Moreover, tenor can be viewed as a rhetorical strategy.

\section{Tenor as a Ehetorical Strategy}

It would be wrong to assume that tenors are always constructed deliberately and do not result from 'natural' relationships. However, the ways people convey these relationships in 'ordinary' everyday conversation and in goal-oriented discourse aimed at effective interaction, projecting a certain image, persuading, and influencing others are very different.

It is necessary to consider here two aspects of tenor: the social and cultural factors that regulate the choice of tenor and its functions in rhetorical discourse.

Admittedly, social and cultural norms have a great influence on rhetorical discourse, its content and style. This influence is realized in the following way: the speaker chooses speech strategies and language means which are appropriate and goal-oriented. Today public speaking is viewed as a two-sided process, in which the interaction of the speaker and the audience is of crucial importance for its effectiveness. Specialists in public speaking (Hughes \& Phillips, 2004) emphasise the role of the listeners: "How should we judge a speech? By its effect on the audience. They are the only judges. Public speaking is a uniquely "democratic" form of expression" (Hughes \& Phillips, 2004, p. 3). This requirement leads to the conclusion that maintaining contact with the listeners is vital for the success of any presentation.

The key concepts that refer to effective interaction of the participants of rhetorical discourse are identification, rapport, and empathy. Identification refers to the search of common language, the ability to identify yourself and others without losing your own identity. Empathy is the ability to share other people's feelings, which contributes to active and open character of rhetorical discourse. Rapport refers to the relations of sympathy and mutual respect between the speaker and the listeners.

It is clear that the choice of tenor is in fact one of contact strategies. The prevalence of informal, friendly tenor in the academic public presentations stated above $(4,1)$ is accounted for by the guidelines for effective interaction of discourse participants. Speakers tend to structure their lectures as "enlarged conversations" with the listeners. The evidence of this can be found in the introductions when informal conversational tenor is used to establish contact and create a favourable first impression:

'Today the sun is shining | and my basic reaction is go and take a walk in the park || (Lecture "Forms of Classroom Interaction", 2012; MPGU Corpus of Spoken English, 2015).

I'd like to start| by sharing with you an interesting experience |which I had four years ago it's difficult to believe,| but four years ago| I had discussions and workshops about culture in English language teaching $\|$ and I always asked at the beginning of these talks the same question |l: What do we mean by culture? |If I say "culture" to you, | what does "culture" mean?||'. (Moscow State Pedagogical University (MSPU), 2015)

It should be noted that that speakers frequently resort to the shift of tenor as a special rhetorical strategy. It can be observed in storytelling, one of powerful techniques of building rapport. A good story or a joke performs a variety of functions: it involves the audience, creates drama, makes the presentation more personal and more expressive. At the same time storytelling can serve as an effective support. Stories often contain the information about the speaker and indicate his being open and ready to share opinions and experiences with the audience:

'I first became interested in this problem |when I went to live in France.| France, |er|, is a place where I've spent a lot of time | and I still do, I go there very very often.|| One of the things that I liked about Francel was that, | er, | they kissed a lot.|| I don't know if you do this here. || I've only been 12 hours in Russia.|| Do you kiss people in Russia? |Not as often as in France.| What I liked about France |is that they |(I lived in Lion)|, they kissed you on both cheeks| which I thought for a shy Englishman| was a very friendly thing to doll'. (Moscow State Pedagogical University (MSPU), 2015)

The tenor in the above extracts can be described as informal, friendly, conversational, and ironic. Prosodic characteristics are similar to those in spontaneous discourse: narrow pitch range, prevalence of MidLevel Tones and Low Falls, Mid and Low Level Tones in pre-nuclear parts of the intonation groups, fast tempo, varied length of pauses, and presence of hesitation pauses.

Change of tenor is particularly vivid when the speakers tell jokes and introduce special characters:

'There was a guy | who was older than us $\|$ And he made a very long presentation $\|$ We were sitting in the back thinking $\|$ Is 
he a genius | or is he crazy?\| At the end of his presentation | the teacher said || "Nick | that was wonderful' || When we asked him why he had done so | he said |"I didn't want to stop his creativity" I'. (Moscow State Pedagogical University (MSPU), 2015)

In such cases the shift from serious informative tenor to conversational, humorous, and ironic tenor is reflected in marked prosodic contrasts.

It is essential to give special attention to irony because it is highly relevant in terms of tenor formation and the perception of tenor, especially in cross-cultural communication.

\section{Ironic Tenor}

Humour and irony are rhetorical devices widely used in public speeches and characterised by a high rhetorical potential. They are also described as a British conversation code.

Traditionally, three dimensions of irony are singled out: rhetorical (trope), existential (attitude to reality) and ontological (an irony of life, an irony of fate). Irony is so pervasive in English discourse that the study of its realisation in public speeches should include both the rhetorical and the existential aspects.

In English, irony is "a default conversational (and possibly deeper-seated psychological) mode" (Thorne, 2009, p. 181).

According to Fox, who emphasises the central importance of humour and irony in English culture, "what is unique about English humour is the pervasiveness of irony and the importance we attach to it. Irony is the dominant ingredient in English humour, not just a piquant flavouring. Irony rules" (Fox, 2005, p. 65).

This research suggests that irony and self-irony permeate British rhetorical discourse, and academic public speeches (lectures) in particular. Ironic phrases can be traced as well as the whole passages which sound ironic. The overall impression is that irony is a constant element of discourse and that its tenor can be described as ironic.

There are many cases of self-irony, which are used to 'lower' the speaker's image, to demonstrate his being on friendly terms with the listeners:

'I have two main interests in life $\|$ and they are not eating and drinking $\|$ (Lecture “Teaching Styles", 2010; MPGU Corpus of Spoken English, 2015)

There is a big division | and it's on class lines | which is defined in this casel by educational level to some extent| between good novels $\mid$ that people like us|Ann and me and Simon and Gregg and Susan| highbrow| I think I'll use this word "highbrow"| that we read||.
And we are very proud of ourselves $\mid$ we feel very superior| we know we are better||l'. (Moscow State Pedagogical University (MSPU), 2015)

Admittedly, prosody, capable of expressing the most subtle shades of meaning, is of crucial importance for conveying irony and ironic tenor. At the same time prosody is a contextualisation cue: it provides a link between the utterance and the context. In other words, due to prosody 'the voicing' can be identified as ironic.

The research showed marked prosodic contrasts between the textual units characterised by ironic tenor and the surrounding textual units. Two tendencies can be traced: 1) contrast due to prosodic prominence; 2) contrast due to 'smoothed' prosody (reduced prosodic parameters). They are illustrated below.

1. 'We read a book| and then we say||'Is that a good book?|| Has it made me more sensitive?"|| That's what we do in our literature seminars| I have to say|| I mean it's a very nice lifell You only read good things| you don't read the rubbish $\|$ It's an absolutely wonderful life $\mid$ and you get paid for it as well||l'. (Moscow State Pedagogical University (MSPU), 2015)

This is an extract from a lecture on literary genres. The lecturer, a university professor, describes her professional activity as an easy and pleasant pastime. Ironic tenor is created with the help of the following prosodic devices: short intonation groups, broad pitch range, repeated use of intonation pattern High Level Head+High Fall. Increased loudness combined with slow speech rate ( $250 \mathrm{msec}$ ) and long syntactic pauses contribute to the effect of prosodic prominence.

2. 'The drinking II'm afraid | should I be afraid I don't know || ah | has increased || Royal Ascot gets features in all newspapers | because ladies go to Royal Ascot as much to show off their hats| as to look at the horses| in fact horses are incidental to the exercisell. (Moscow State Pedagogical University (MSPU), 2015)

In both extracts from the lecture on social and economic problems irony is realised as Low Key information: low pitch level, narrow pitch range, increased tempo, and reduced loudness.

Mid-Level Tone is frequently used to convey irony. 'We feel very proud of ourselves II we feel very superior $\|$ we know we are better II. (Moscow State Pedagogical University (MSPU), 2015)

In first two intonation groups, High Level Head is used in combination with the Fall-Rise and the High Fall correspondingly. In the third intonation group, the Mid-Level Tone provides a contrast.

Paralinguistic signals also contribute to creating 
ironic tenor. On the one hand, 'relaxed voice', and 'a phonetic smile' indicate that the speaker is not serious; on the other hand, 'a tense voice' or affected seriousness may be indicators of bitter irony or sarcasm.

The main tendencies in the prosodic realisation of ironic tenor are presented in Table 1.

Table 1

Prosodic markers of ironic tenor

\begin{tabular}{lll}
\hline Prosodic markers & \multicolumn{1}{c}{$\begin{array}{c}\text { Exaggerated } \\
\text { prosody }\end{array}$} & Levelled prosody \\
\hline Terminal tones & $\begin{array}{l}\text { High Fall, Mid } \\
\text { Fall, Fal-Rise, } \\
\text { Rise-Fall-Rise }\end{array}$ & $\begin{array}{l}\text { Low Fall, Low Rise, } \\
\text { Mid Level Tone }\end{array}$ \\
\hline $\begin{array}{l}\text { Pre-nuclear } \\
\text { patterns }\end{array}$ & $\begin{array}{l}\text { Sliding Head, High } \\
\text { Level Head, Step- } \\
\text { ping Head }\end{array}$ & $\begin{array}{l}\text { Mid Level Head, } \\
\text { Low Level Head }\end{array}$ \\
\hline Tempo & Comparatively slow & Comparatively fast \\
\hline Segmentation & $\begin{array}{l}\text { Short and medium } \\
\text { intonation groups }\end{array}$ & $\begin{array}{l}\text { Medium, long, very } \\
\text { long intonation } \\
\text { groups }\end{array}$ \\
\hline Pauses & $\begin{array}{l}\text { Syntactic pauses } \\
\text { (medium, long), }\end{array}$ & $\begin{array}{l}\text { Syntactic pauses } \\
\text { (medium, short, } \\
\text { very short) }\end{array}$ \\
\cline { 2 - 3 } & $\begin{array}{l}\text { Emphatic pauses } \\
\text { (medium, long) }\end{array}$ & Hesitation pauses \\
\hline Voice & $\begin{array}{l}\text { Tense voice, serious } \\
\text { voice }\end{array}$ & $\begin{array}{l}\text { Neutral voice, } \\
\text { creaky voice }\end{array}$ \\
\hline Articulation & $\begin{array}{l}\text { Exaggerated articu- } \\
\text { latory precision, af- } \\
\text { fected articulation }\end{array}$ & No specific features \\
\hline Articulation & $\begin{array}{l}\text { Exaggerated articu- } \\
\text { latory precision, af- } \\
\text { fected articulation }\end{array}$ & No specific features \\
\hline
\end{tabular}

Concluding this brief overview of the prosodic markers of ironic tenor, it is necessary to point out that the adequate interpretation of ironic 'voicing' is particularly challenging for non-native speakers of English. The participants of cross-cultural communication who fail to read the prosodic signals might make wrong inferences about the speaker's communicative intentions. As Coupland puts it, "irony is a quagmire for reading acts of identity, because 'as if' identities can wholly subvert the apparent meaning of a projection" (Coupland, 2007, p. 114).

\section{Conclusion}

The results of the research presented in this article demonstrate the significance of tenor in rhetorical discourse. Tenor conveys the information both about the character of participants' relationships in a given speech situation and about the relationships determined by the social and cultural context.
Moreover, tenors can change in the course of the speech event.

Tenor shifts can be used as a rhetorical strategy and perform a number of functions in a public speech. They can serve to build rapport with the audience and maintain contact, they contribute to the expressiveness of the discourse, they are used in rhetorical argumentation. Tenor can also be viewed as a means of projecting the speaker's identity and the speaker's image.

The vocal features (prosody in particular) are of crucial importance for conveying and identifying tenors. As a contextualization cue prosody provides the links between the message and the social context of interaction. The prosodic markers of tenor include pitch parameters, rate of speech, and the character of pauses. The data obtained in the research demonstrated marked difference in the set of prosodic parameters typical of formal (informative) and informal (conversational) tenors.

Adequate identification of tenors is highly relevant in cross-cultural communication. It is hoped that some of the observations made in this paper might be useful both for the development of the sociocultural competence of Russian learners of English and for improving their rhetorical skills.

\section{References}

Bloch, M., \& Freydina, E. (2011). Publichnaya rech i yeye prosodicheskyi stroy [Public speech and its prosodic organisation]. Moscow, Russia: Prometey.

Couper-Kuhlen, E., \& Selting, M. (1996). Prosody in conversation. Interactional studies. Cambridge, UK: Cambridge University Press.

Coupland, N. (2007). Style: Language variation and identity. Cambridge, UK: Cambridge University Press.

Downes, W. (1998). Language and society (2nd ed.). Cambridge, UK: Cambridge University Press.

Fox, K. (2005). Watching the English. The hidden rules of English behaviour. London, UK: Hodder and Stroughton.

Freydina, E. (2013). Phonostylistichesky aspect academicheskoy publichnoy rechi [Phonostylistic aspect of academic presentations]. In E. L. Freydina (Ed.), Prosodia publichnoy rechi (pp. 7-36). Moscow, Russia: Prometey.

Gregory, M., \& Carroll, S. (1978). Language and situation. Language varieties and their social contexts. London, UK: Routledge and Kegan Paul.

Hughes, D., \& Phillips, B. (2004). The Oxford union guide to speaking in public. Oxford, UK: Virgin Publishing. 
Karasik, V. (2009). Yazyukovye kluchi [Language keys]. Roach, P. (2000). English phonetics and phonology. Moscow, Russia: Gnozis.

Cambridge, UK: Cambridge University Press.

Kreydlin, G. (2000). Golos i ton v yazyuke i rechi Schevchenko, T. (2015). Sociophonetica. Natzionalnaya [Voice and tone in language and speech]. In N. D. Arutyunova (Ed.), Yazyuk o yazyuke (pp. 453-501). Moscow, Russia: Yazyuki Russkoy Kultury. $i$ sozialnaya identichnost $v$ Anggliskom proiznoshenii [Sociophonetics. National and social identity in English pronunciation]. Moscow, Russia: URSS.

Moscow State Pedagogical University. (2015). Corpus Thorne, T. (2009). The 100 words that make us English. of spoken English. Moscow, Russia: MPGU. London, UK: Abacus. 